\title{
Validity and reliability of the Turkish version of CRAFFT Substance Abuse Screening Test among adolescents
}

This article was published in the following Dove Press journal:

Neuropsychiatric Disease and Treatment

22 June 2015

Number of times this article has been viewed

\author{
Hasan Kandemir' \\ Ömer Aydemir ${ }^{2}$ \\ Suat Ekinci ${ }^{3}$ \\ Salih Selek ${ }^{4}$ \\ Sultan B Kandemir ${ }^{5}$ \\ Hüseyin Bayazit ${ }^{6}$ \\ 'Department of Child and Adolescent \\ Psychiatry, School of Medicine, Harran \\ University, Sanliurfa, ${ }^{2}$ Department of \\ Psychiatry, School of Medicine, Celal \\ Bayar University, Manisa, ${ }^{3}$ Balıklı Rum \\ Hospital, İstanbul, ${ }^{4}$ Department of \\ Psychiatry and Behavioral Sciences, \\ University of Texas Health Science \\ Center, Houston, Texas, USA; \\ ${ }^{5}$ Department of Psychiatry, Balikligol \\ State Hospital, Sanliurfa, ${ }^{6}$ Department \\ of Psychiatry, School of Medicine, \\ Harran University, Sanliurfa, Turkey
}

Aim: This study aimed to validate the CRAFFT diagnostic test, against the Diagnostic and Statistical Manual of Mental Disorders - Fourth Edition, Axis 1-based diagnostic inventory in a Turkish population of adolescents.

Method: The 124 adolescents who were 15-18 years old were enrolled to this study. CRAFFT was self-administered. Interviews took approximately 30 minutes, including the DSM-IV diagnostic interview for alcohol/drug dependence.

Results: The mean age of subjects was 16.653 years (minimum: 15 years, maximum: 18 years). A score of 2 or higher in part B was found to be optimal for detecting youths with substance dependence problems (sensitivity: 0.82; specificity: 0.88) and it was sufficiently discriminative.

Conclusion: The CRAFFT is a valid and reliable instrument for identifying Turkish-speaking youths at risk for substance use disorders.

Keywords: CRAFFT, substance abuse, validity, Turkish, adolescent

\section{Introduction}

Substance use and abuse constitute one of the major public health problems in the world. According to the World Health Organization, the harmful use of alcohol results in 2.5 million deaths each year and 320,000 young people between the age of 15 years and 29 years die from alcohol-related causes, resulting in $9 \%$ of all deaths in that age group. ${ }^{1}$ At least 15.3 million persons have drug use disorders. Recent estimates are that in $2008,155-250$ million people, or $3.5 \%-5.7 \%$ of the world's population, aged 15-64 years used other psychoactive substances, such as cannabis, amphetamines, cocaine, opioids, and nonprescribed psychoactive prescription medication. ${ }^{1}$ The use of psychoactive substances causes significant health and social problems for the people who use them, as well as for others in their families and communities. ${ }^{1}$ It is reported that use of drugs by at least one parent/guardian is independently associated with higher odds of mental health problems. ${ }^{2-5}$

\section{Background}

Alcohol and drug use typically begins during adolescence and it is associated with increased risk of addictive disorders in later life. ${ }^{6,7}$ Data from the 2005 National Survey on Drug Use and Health indicated that all levels of drinking, from use to binge drinking to heavy drinking, increase with increasing age during adolescence. ${ }^{8}$ Alcohol dependence typically emerges during late adolescence or early adulthood. ${ }^{9}$ One study in Turkey showed that high school students (aged 15-17 years) had ever
Department of Child and Adolescent Psychiatry, Harran University, School of Medicine, Yenisehir, Sanliurfa 63100 , Turkey

Tel +904143183000

Fax +904143183190

Email kandemirhsn@yahoo.com 
used prevalence of $3 \% .{ }^{10}$ In an international study, it has been stated that nearly every third adolescent reported some degree of alcohol/drug use during the past 12 months. ${ }^{11}$ Experimentation with and use of substance in childhood and adolescence carries a potential risk for later development of substance use disorders in adulthood. ${ }^{12}$ Alcohol and drug use was significantly associated with lower levels of quality of life and physical, emotional, and school functioning scores among adolescents. ${ }^{11}$ The use of alcohol and other drugs is associated with the leading causes of death among teens, unintentional injury (including motor vehicle crashes), homicides, and suicides. ${ }^{13}$

The American Medical Association's Guidelines for Adolescent Preventive Services recommend that health care providers ask all adolescent patients annually about their use of drugs as part of routine care. ${ }^{14}$ General practitioners and pediatricians have a very important role in terms of identification of problems and providing brief advice and intervention. Diagnosis based on the Diagnostic and Statistical Manual of Mental Disorders - Fourth Edition (DSM-IV) criteria requires a detailed clinical interview, which is not practical in a busy primary care or community setting. The ideal instrument for screening adolescents and diagnosing must be developmentally appropriate, valid and reliable, and practical for use in busy medical offices. ${ }^{15}$ To be practical, it must be easy to administer, score, and remember. Clinicians who aim to test new therapies must have reliable screens to identify both teens in need of treatment and reliable outcome measures to track their progress. Most screening instruments were specifically developed to detect alcohol-related problems among adults. Knight et $\mathrm{al}^{16}$ have developed a brief screening device for use among adolescents, the CRAFFT test, which is a six-item instrument with individual questions. It has been found that the interview-administered CRAFFT has good criterion validity for identifying teens with substance-related disorders ${ }^{13}$ and the CRAFFT screen had acceptable internal consistency. ${ }^{16}$

The aim of this study was to determine the reliability and validity of the CRAFFT diagnostic test, against the DSM-IV diagnostic inventory in a Turkish population of adolescents.

\section{Materials and methods}

First, permission was obtained from John R Knight, MD at the Center for Adolescent Substance Abuse Research, Division of Developmental Medicine, Boston Children's Hospital, Harvard Medical School, MA, USA. CRAFFT has been translated to Turkish, but it has not validated.
The translated version was received from the Center for Adolescent Substance Abuse Research. Authors translated it again and after back translation, the instrument was administered. For concurrent validity, the DSM-IV was used.

The 124 adolescents enrolled to this study were 15-18 years old. Subjects with substance dependence were mostly selected from an inpatient clinic of a general hospital's psychiatric department, and other participants were selected from the same clinic's outpatient part; persons who accepted to enroll in the study made up the sample. Consents were taken from parents and participants. No study incentive or gift was given to the participants. All of the study procedures were in accordance with the Declaration of Helsinki. Ethics committee of the Harran University Medical School approved the trial. The final patient and control groups displayed similar distribution in terms of age and sex. CRAFFT was selfadministered. Interviews took approximately 30 minutes, including the DSM-IV diagnostic interview. Interviews were conducted in a private space by a psychiatrist, and the participants were told that the information would be kept confidential.

The CRAFFT is a screening tool for problematic alcohol or drug use among adolescents in the past 1 year. It includes two parts. The first part has three items that evaluate whether the adolescent used alcohol, cannabis, and other substances in the preceding 1 year.

The second part of the CRAFFT has six items, which investigate whether the adolescent had used the substance. Its name is a mnemonic of the first letters of key words in the test's six questions. ${ }^{14}$ The sign of substance abuse in the CRAFFT instrument includes the following: having ridden in a "car" driven by someone (including self) when high on alcohol or other substances; having used alcohol or other substances to "relax" or feel better about her/himself; having used alcohol or other substances while by her/ himself "alone"; and having "forgotten" to complete a task while using alcohol or other substances. Other items on the CRAFFT include whether "family or friends" ever told the adolescent that she/he should cut down on alcohol or other substance use and whether the adolescent ever had "trouble" with the law while using alcohol or other substances.

The answer choices were "Yes" (1 point) or "No" (0 point) for all items. CRAFFT scores, which are the sum of responses to the questions from the second part, can range from 0 to 6 . Greater values may indicate more problematic use. ${ }^{15}$

The analyses were performed using SPSS for Windows 15.0. We examined sensitivity, specificity, and receiver operating characteristic (ROC) areas under the curve (AUC) to 
determine the optimal CRAFFT cutoff point(s) for predicting any substance use disorder demographic frequencies, means, and standard deviations were determined. Sensitivity, specificity, and positive and negative predictive values (PPV and NPV) were calculated.

\section{Results}

The adolescents enrolled in this study were 124 in number and were aged 15-18 years. The mean age of the subjects was 16.653 years (minimum 15 years, maximum 18 years). Sociodemographic information is shown in Table 1. According to DSM-IV criteria, 34 subjects had substance use disorders: 18 people used heroin, two people used inhalant, seven people used cannabis, and seven people used mixed substances. Of all adolescents surveyed, 72.6\% reported no substance use. Proportion of substance dependence is also shown in Table 1. A score of 2 or higher in part B was found to be optimal for detecting youths with substance use problems (sensitivity: 0.82; specificity: 0.88 ), and it was sufficiently discriminative. PPV and NPV found to be PPV: $71.79 \%$ (95\% confidence interval [CI]: 55.12\%-84.98\%; NPV: 92.94\% (95\% CI: $85.26 \%-97.35 \%)$. Percentages of subjects responding "yes" to each CRAFFT item, the percentage that had score of " 0 " to "6", and the best CRAFFT score cutoff point based on sensitivity and specificity are given in Tables $2-4$, respectively. The ROC curve is shown in Figure 1.

\section{Discussion}

This study provides evidence that the CRAFFT is a promising brief diagnostic instrument for alcohol and other drug use disorders among Turkish youth. Short diagnostic methods for finding out problems with alcohol or other addictive substances are essential for clinicians. Questionnaires about substance use disorders are especially used to

Table I Sociodemographic information and proportion of substance dependence

\begin{tabular}{lll}
\hline Substance & $\mathbf{N}$ & $\%$ \\
\hline Cannabis & 7 & 5.6 \\
Heroin & 18 & 14.5 \\
Inhalant & 2 & 1.6 \\
Mixed substance & 7 & 6.6 \\
Nothing & 90 & 72.6 \\
Sex & & \\
$\quad$ Male & $85(68.5 \%)$ & \\
$\quad$ Female & $39(31.5 \%)$ & \\
Age & & \\
$\quad$ Minimum-maximum (years) & $15-18$ & \\
Mean (years) & $16.66 \pm 80$ & \\
\hline
\end{tabular}

Table 2 The percentage of subjects responding "yes" to each CRAFFT item

\begin{tabular}{ll}
\hline Items & Answers "yes" (\%) \\
\hline Car & 27.4 \\
Relax & 30.6 \\
Alone & 29.0 \\
Forgotten & 26.6 \\
Family/friend & 34.7 \\
Trouble & 19.4 \\
\hline
\end{tabular}

identify adults with drinking problems. Alcohol and drug use typically begins during adolescence and it is associated with increased risk of addictive disorders in later life. ${ }^{6,7}$ It is also significantly associated with lower levels of quality of life among adolescents. ${ }^{9}$ Therefore, it is important to screen young people for substance abuse and to diagnose dependence.

We need a tool that must be brief and easy to administer in a primary care setting, which will make it well suited for clinical practice and research. We can recommend the CRAFFT as a practical and reliable measure for quantifying drug and alcohol consumption with adolescents. It is important to use culturally and developmentally appropriate assessments when working with native populations. Previous studies have determined the usefulness of the CRAFFT in general adolescent populations. ${ }^{15,16}$ The Turkish version of CRAFFT is well comparable to results acquired by other studies. ${ }^{4,14,15}$ The CRAFFT showed high levels of consistency (Cronbach's alpha: 0.9014) which is comparable to scores found in other studies $\left(0.68,0.73,0.81\right.$, respectively). ${ }^{7,15,17}$ The sensitivity and specificity found in this study for the dependence category were 0.82 and 0.88 , respectively, and they are close to those reported in previous studies. ${ }^{15,16}$

It is suggested that while a clinician can be reasonably reassured when CRAFFT is negative, the patient should be further assessed when it is positive. The CRAFFT scale is a screening tool, but its score is correlated with increasing severity of diagnostic classification. Knight et $\mathrm{al}^{15}$ recommended a cutoff score of 2 , and one study recommended a

Table 3 Percentage of participants that had scores of "0" to " 6 "

\begin{tabular}{ll}
\hline CRAFFT score & $\%$ \\
\hline 0 & 52.4 \\
1 & 4.8 \\
2 & 11.3 \\
3 & 8.9 \\
4 & 6.5 \\
5 & 8.9 \\
6 & 7.3 \\
\hline
\end{tabular}


Table 4 The best CRAFFT score cutoff point based on sensitivity and specificity

\begin{tabular}{lll}
\hline Score & Sensitivity & Specificity \\
\hline 1 & 97.05 & 77.77 \\
2 & 82.35 & 87.77 \\
3 & 70.58 & 95.55 \\
4 & 52.94 & 97.77 \\
5 & 26.47 & 100.00 \\
6 & 0.00 & 100.00 \\
\hline
\end{tabular}

cutoff score of 1 for Asian populations. ${ }^{7}$ Cummins suggested that a score of 2 or higher should serve as an indication that at a minimum, further assessment for cannabis and alcohol use is necessary, and a score of 3 or higher may warrant more intensive evaluation. ${ }^{17} \mathrm{~A}$ score of 2 or higher was found to be optimal for detecting youths with substance use disorders and it was sufficiently discriminative in our study. These results are consistent with those from previous studies. Most of the studies examined the performance of the CRAFFT in identifying any problem use (defined as one or more DSM criteria) and any DSM substance use disorder (two or more DSM criteria) for alcohol or drugs other than tobacco. All studies have used CRAFFT as a screening tool in a population sample and its validity was only evaluated by concurrent self-reported measures. We selected our substance use disorder patients from an inpatient clinic and we used DSM-IV substance dependence criteria as gold standard. Although our sample consisted of more severe subjects with substance dependence disorder, we found same cutoff

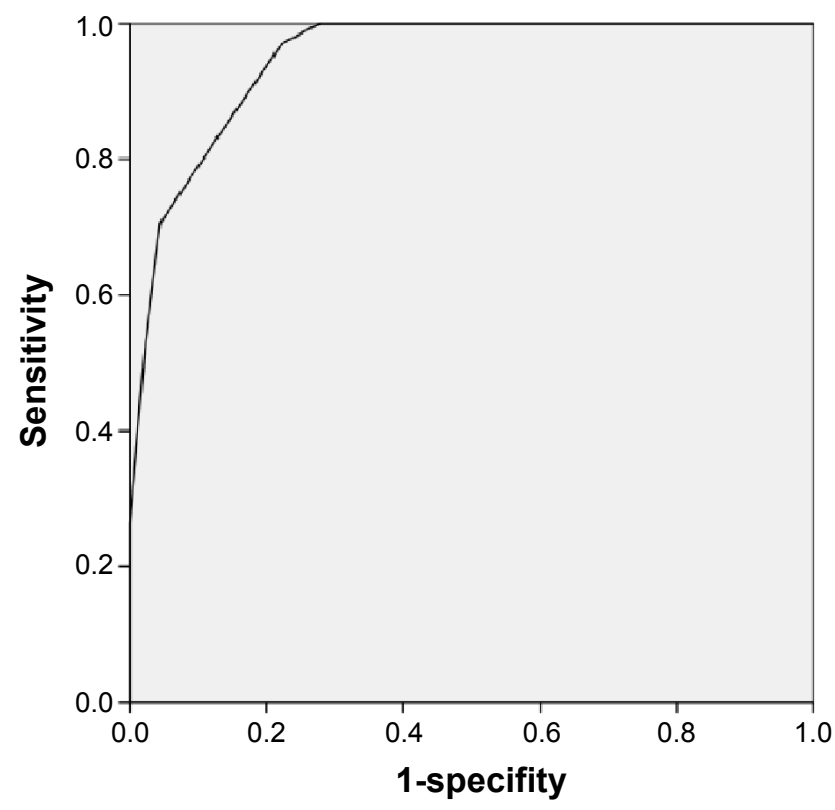

Figure I Area under the ROC curve.

Abbreviation: ROC, receiver operating characteristic. scores with previous studies. Social and cultural context and personality are also important aspects; these should be taken into consideration for different cutoff scores. ${ }^{18}$

\section{Conclusion}

Experiences with the Turkish version of the CRAFFT confirm its applicability as a practical screening tool for establishing substance use disorders by adolescents.

\section{Disclosure}

The authors report no conflicts of interest in this work.

\section{References}

1. WHO. Management of Substance Abuse. Facts and Figures. WHO 2008. Available from: http://www.who.int/substance_abuse/facts/en/

2. Stevanovic D, Urbán R, Atilola O, et al. Does the Strengths and Difficulties Questionnaire - self report yield invariant measurements across different nations? Data from the International Child Mental Health Study Group. Epidemiol Psychiatr Sci. 1-12. Epub 2014 April 30.

3. Ekinci S, Kandemir H. Childhood trauma in the lives of substance dependent patients: the relationship between depression, anxiety and self esteem. Nord Psychiatry. Nordic Journal of Psychiatry. 2015;69(4): 249-253.

4. Stevanovic D, Atilola O, Balhara YPS, et al. The relationships between alcohol/drug use and quality of life among adolescents: an international, cross-sectional study. J Child Adolesc Subst Abuse. Published online: 13 Jan 2015.

5. Ekinci S, Kandemir H. The frequency of co-occuring disorders, childhood trauma and self-esteem in the parents of substance dependent individuals. J Psychiatry. 2015;18(2):1-3.

6. Grant JD, Scherrer JF, Lynskey MT, et al. Adolescent alcohol use is a risk factor for adult alcohol and drug dependence: evidence from a twin design. Psychol Med. 2006;36(1):109-118.

7. Subramaniam M, Cheok C, Verma S, Wong J, Chong SA. Validity of a brief screening instrument-CRAFFT in a multiethnic Asian population. Addict Behav. 2010;35(12):1102-1104

8. Substance Abuse and Mental Health Services Administration. Results from the 2005 National Survey on Drug Use and Health: National Findings. Rockville, MD: Substance Abuse and Mental Health Services Administration, NSDUH Series H-30, DHHS Publication SMA 06-4194; 2006

9. Grant BF, Dawson DA, Stinson FS, Chou SP, Dufour MC, Pickering RP. The 12-month prevalence and trends in DSM-IV alcohol abuse and dependence: United States, 1991-1992 and 2001-2002. Drug Alcohol Depend. 2004;74(3):223-234.

10. Ögel K, Çorapçıglu A, Sır A. Tobacco, alcohol and substance use prevalence among elementary and secondary school students in nine cities of Turkey. Turkish Journal of Psychiatry. 2004;15(2): $112-118$.

11. Atilola O, Stevanovic D, Balhara YP, et al. Role of personal and family factors in alcohol and substance use among adolescents: an international study with focus on developing countries. J Psychiatr Ment Health Nurs. 2014;21(7):609-617.

12. Winters KC, Lee CY. Likelihood of developing an alcohol and cannabis use disorder during youth: association with recent use and age. Drug Alcohol Depend. 2008;92(1-3):239-247.

13. Kann L, Kinchen S, Shanklin SL, et al. Youth risk behavior surveillanceUnited States, 2013. Morb Mortal Wkly Rep Surveill Summ. 2002; 2014(63 suppl 4):1-168.

14. Elster A, Kuznets N, editors. Guidelines for Adolescent Preventive Services (GAPS). Baltimore, MD: Williams \& Wilkins; 1994. 
15. Knight JR, Sherritt L, Shrier LA, Harris SK, Chang G. Validity of the CRAFFT substance abuse screening test among adolescent clinic patients. Arch Pediatr Adolesc Med. 2002;156(6):607-614.

16. Knight JR, Shrier LA, Bravender TD, Farrell M, Vander Bilt J, Shaffer HJ. A new brief screen for adolescent substance abuse. Arch Pediatr Adolesc Med. 1999;153(6):591-596.

17. Cummins LH, Chan KK, Burns KM, Blume AW, Larimer M, Marlatt GA. Validity of the CRAFFT in American-Indian and AlaskaNative adolescents: screening for drug and alcohol risk. J Stud Alcohol. 2003;64(5):727-732.
18. Atilola O, Singh Balhara YP, Stevanovic D, Avicenna M, Kandemir H. Self-reported mental health problems among adolescents in developing countries: results from an international pilot sample. J Dev Behav Pediatr. 2013;34(2):129-137.

\section{Publish your work in this journal}

Neuropsychiatric Disease and Treatment is an international, peerreviewed journal of clinical therapeutics and pharmacology focusing on concise rapid reporting of clinical or pre-clinical studies on a range of neuropsychiatric and neurological disorders. This journal is indexed on PubMed Central, the 'PsycINFO' database and CAS, and is the official journal of The International Neuropsychiatric Association (INA). The manuscript management system is completely online and includes a very quick and fair peer-review system, which is all easy to use. Visit http://www.dovepress.com/testimonials.php to read real quotes from published authors.

Submit your manuscript here: http://www.dovepress.com/neuropsychiatric-disease-and-treatment-journal 